\title{
The Prevalence of Chronic Diseases among $\mid$ Original The Prevalence of Chronic Diseases among $\mid$ Article Migrants in Korea According to Their Length of Stay and Residential Status
}

\author{
Choong-Hyung Lee, Jae-Moon Yun, Jong-Soo Han, Sang-Min Park, \\ Young-Su Park ${ }^{1}$, Seung-Kwon Hong ${ }^{2, *}$
}

Department of Family Medicine, Seoul National University College of Medicine, Seoul; ${ }^{1}$ Department of Anthropology, Seoul National University College of Social Sciences, Seoul; ${ }^{2}$ Department of Family Medicine, Incheon St. Mary's Hospital, The Catholic University of Korea School of Medicine, Incheon, Korea

Background: Migrant health is becoming public health issues, as the migrant populations are increasing and their length of stay is prolonged. This study aims to analyze the differences in prevalence of chronic diseases among migrants according to length of stay and residential status.

Methods: An initial population pool were 3,024 who were assessed with health screening programs by Migrant Health Association. 2,459 migrants were selected for final analysis. Via Stata 10 we conducted univariate logistic regression analysis to examine the effects of their length of stay and residential status on the prevalence of hypertension, diabetes, dyslipidemia, and obesity. In the final analysis, the result of each sex was adjusted for age, nationality, length of stay, and residential status via multiple logistic regression analysis.

Results: Longer length of stay tends to increase the prevalence of hypertension in male; 4-6 year stay-duration group demonstrated statistically significant excess compared to 1 year or less stay-duration group (adjusted odds ratio [OR], 1.39; confidence interval [CI], 1.01 to 1.92). After adjustment, male migrants stayed more than 7 year showed considerably higher dyslipidemia than male migrants stayed less than 1 year (adjusted OR, 1.95; CI, 1.05 to 3.64). Compared to the group with 1 year or less stay-duration, the prevalence of obesity in male was significantly higher among 4-6 year (adjusted OR, 1.65; CI, 1.17 to 2.32) and 7 year or more stay-duration group (adjusted OR, 1.65; CI, 1.11 to 2.45).

Conclusion: Longer length of stay correlated to higher prevalence of hypertension, dyslipidemia, and obesity among some population of migrants. So more researches and new developing policies are needed for this problem.

Keywords: Transients and Migrants; Hypertension; Diabetes; Dyslipidemia; Obesity

\section{INTRODUCTION}

Received: August 30, 2010, Accepted: January 16, 2012

*Corresponding Author: Seung-Kwon Hong

Tel: +82-1544-9004, Fax: +82-1544-9004

E-mail: SKYiHong@facebook.com

Korean Journal of Family Medicine

Copyright (C) 2012 The Korean Academy of Family Medicine

(a) This is an open-access article distributed under the terms of the Creative Commons Attribution Non-Commercial License (http://creativecommons.org/licenses/by-nc/3.0) which permits unrestricted noncommercial use, distribution, and reproduction in any medium, provided the original work is properly cited.
In the year 2009, the number of foreign migrants residing in South Korea came to be about 1,117,000 amounting 2.4\% of the total population, whereas, in the year 1990, it was about 50,000 amounting only $0.1 \%$. When we put our low birth rate, increasing tendencies of international marriages among Koreans, shortage of manufacturing manpower and general effects of globalization into considerations, the number of migrants in South Korea is expected to increase. 
Where the number of migrants is on the increase, human rights violations and discriminations are still remained in Korean society. Amnesty International recommended that the government of Republic of Korea should immediately guarantee the migrant workers' rights and safety by prohibiting discriminations and complying with their rights in workplaces, rights of freedom to associate and freedom to move their workplaces. ${ }^{2)}$ In addition to these discriminations and deprivation of rights, various national studies are reporting the present status of the migrant workers: low income level, poor living environments, ${ }^{3)}$ accident-prone industrial workplace environments, ${ }^{4)}$ lack of job security and status stability, racial discrimination $^{2)}$ and accordingly human rights violations, language barrier and stresses from adjusting to new culture and environment, lack of social network, ${ }^{5)}$ and low access to medical services.

It is well-known from various studies that an individual's health in low socio-economic status group are poor, ${ }^{7,8)}$ seen from their present socio-economic environment, the migrant workers' health status are assumed to be poor as well. It has, already, reported from various domestic observational studies that in cases of migrant workers they frequently die from curable diseases like pneumonia or peritonitis, many cases of musculoskeletal diseases and headache, ${ }^{9)}$ high prevalence rates of hypertension and dyslipidemia, etc. ${ }^{10)}$ However, there have been no representative and systemic studies dealing with migrants.

Nevertheless, considering the increment in the number of migrants and their tendencies for prolonged stay, it is expected that their prevalence rates of chronic diseases like hypertension, diabetes and dyslipidemia will be on the increase; in case of these chronic diseases, if not cared adequately it would likely to increase the social expenses as well as be bad influence to their health that immediate attention is needed to assess their status regarding chronic diseases and to make an management plan from primary healthcare perspectives.

As with migrants' length of stay increases, various studies have been conducted outside Korea reporting that chronic diseases like obesity or hypertension are on the increase as well, ${ }^{11)}$ whereas there has been no domestic study on the subject. In addition, there are 200,000 undocumented migrants who are of unstable status and not eligible to the National Health Insurance benefits, and studies regarding their differences compared to the documented counterparts is also lacking. Thus, in this study, I'd like to compare the prevalence of chronic diseases like hypertension, diabetes, dyslipidemia, and obesity among migrants, depending on their length of stay and residential status in Korea.

\section{METHODS}

\section{Study Population}

Data was obtained from free health screening tour program around Seoul and Gyeonggi-do by the Migrant Health Association. From 2004 to 2008, health screening tour team travelled around Seoul and Gyeonggi-do once a month to examine health status of migrants. Anyone who wants to examine one's health status was enrolled. Only secondary data excluding personal information were used for the purpose of this study. The number of total data, that is 3,024 , was collected and the number of the examinees were 569 in the year 2004, 721 in 2005, 462 in 2006, 706 in 2007, and 566 in 2008. Among them, those under age 18 or whose nationality were Korean were excluded then those who didn't responded their age, their admission date to Korea were also excluded, and finally 2,459 subjects were selected for the study (Figure 1).

Participants in free health examination
operated by Migrant Health Association in Korea from 2004 to $2008(n=3,024)$

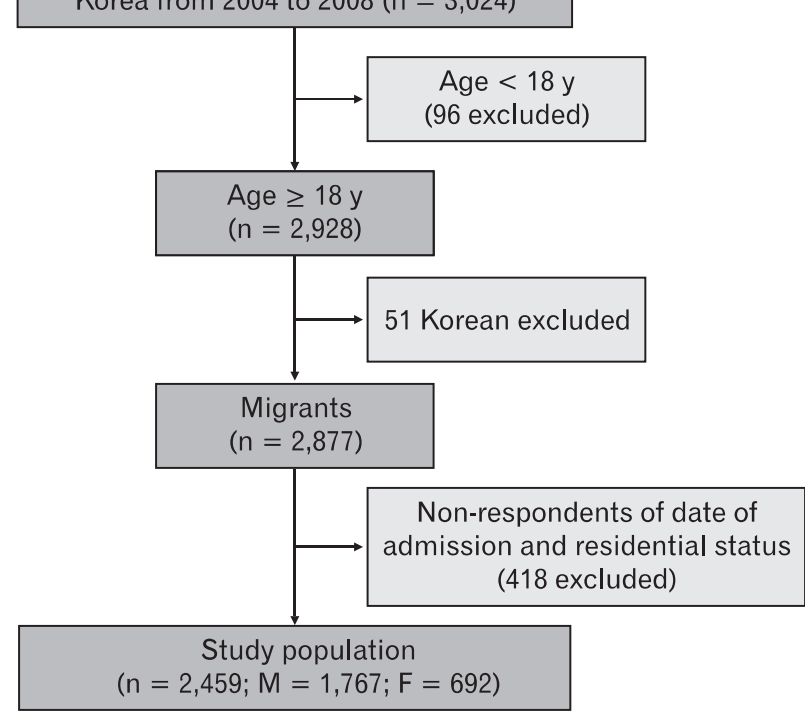

Figure 1. The study population framework. 


\section{Methods}

Data for 'Length of stay' was calculated using the admission date in the health consultation data and the date of their consultation. By quartile, the subjects were divided into length-ofstay groups of 'less than 1 year,' ' 2 to 3 year,' ' 4 to 6 year,' and 'more than 7 year'. For analysis, they were divided into 'documented' and 'undocumented' migrants according to their eligibility to stay, and, by quartile, into age groups of 'less than 30,' '30 to 34,' ' 35 to 39,' 'over 40,' and into respective sex.

Outcome variables like 'hypertension,' 'diabetes,' 'dyslipidemia,' and 'obesity' were defined respectively as a group whose systolic blood pressure is over $140 \mathrm{~mm} \mathrm{Hg}$ or diastole blood pressure over $90 \mathrm{~mm} \mathrm{Hg}$, a group whose blood sugar level is over $126 \mathrm{mg} / \mathrm{dL}$ from the blood test, a group whose total cholesterol level is over $240 \mathrm{mg} / \mathrm{dL}$, and a group whose body mass index (BMI) is over $25 \mathrm{~kg} / \mathrm{m}^{2}$.

Ten statistics program was used in analysis and demographic analysis as well as morbidity rates of respective disease were stated. Univariate logistic regression analysis was used to see whether there were any prevalence rate differences in hypertension, diabetes, dyslipidemia, and obesity, depending on independent variables like 'age,' 'length of stay,' or 'residential status'; Multivariate logistic regression was used in final analysis, adjusted with 'age,' 'nationality,' 'length of stay,' and 'residential status' variables.

\section{RESULTS}

\section{Baseline Characteristics of the Study Population}

In this study, 1,767 people were male, which accounts for $71.9 \%$ of the total number of 2,459 subjects, and 692 were female, which accounts for $28.1 \%$. The average age of the subjects was 35.4 years old. In case of male, it was 33.4 years old and female 37.2 years old that females were 3.8 years older than their counterparts.

The average length of stay in Korea was 4.0 years, and those who have stayed less than 1 year accounted for $27.0 \%$, and $2-3$ years $25.8 \%$, 4-6 years $27.7 \%$, and long term like more than 7 years $19.5 \%$ of the total subjects.

The number of documented migrants were 965 (39.2\%) and undocumented 1,494 (60.8\%). Those who participated in the program were from 32 countries; Bangladeshis were the largest with 470 members (19.1\%), and the next were Mongolians, Filipinos, Vietnamese, Sri Lankan, and Chinese in respective orders (Table 1).

\section{Prevalence of Chronic Diseases}

Among total of 2,459 subjects, 2,393 had records of their blood pressure and 736 had hypertension, accounting for $30.8 \%$. There were sex difference in the prevalence of hypertension that for male it was $32.9 \%$ and female $25.2 \%$. Among 1,850 subjects with blood sugar level records, 249 (13.5\%) had diabetes; male with diabetes accounted for $15.4 \%$ and female $8.8 \%$. For 1,886 subjects with cholesterol level records, 248 subjects, accounted for $13.2 \%$, had dyslipidemia. The prevalence rates were $13.3 \%$ for male and $12.7 \%$ for female. For obesity, among 2,254 subjects $34.2 \%$ had BMI over $25 \mathrm{~kg} / \mathrm{m}^{2}$, and for male $35.8 \%$ were shown to be obese and for female $30.3 \%$ (Table 1).

\section{Age-related Differences in Prevalence Rates of Chronic Diseases}

For male subjects, the prevalence of hypertension was found to be $26.9 \%$ for those aged under 30 and $43.1 \%$ for over 40 . In case of diabetes, the prevalence was $9.1 \%$ for those under 30 and $26.9 \%$ for over 40 , and, dyslipidemia, it was $6.2 \%$ for those aged under 30 and $21.1 \%$ for over 40 . In case of obesity, it was $22.0 \%$ for those under 30 and $51.3 \%$ for those over 40 (Table 2).

For female subjects, the prevalence rate of hypertension was found to be $8.5 \%$ for those aged under 30 and $39.4 \%$ for over 40 , the prevalence of diabetes was $5.2 \%$ for those under 30 and $13.4 \%$ for over 40 , the prevalence rate of dyslipidemia was $5.5 \%$ for those over 30 and $20.9 \%$ for those over 40 , and the prevalence of obesity was $11.5 \%$ for those over 30 and $36.8 \%$ for those over 40 (Table 2).

\section{Length of Stay Related Prevalence of Chronic Diseases}

For male subjects, long-stay group showed to have higher prevalence of the chronic diseases like hypertension, diabetes, dyslipidemia, obesity, etc. than short-stay group. In case of hypertension, $28.3 \%$ of those who stayed less than 1 year had hypertension, where it was $35.3 \%$ for those who stayed $4-6$ 
Table 1. Characteristics of the study population.

\begin{tabular}{|c|c|c|c|c|}
\hline & & Male $(\mathrm{n}=1,767)$ & Female $(n=692)$ & Total $(\mathrm{n}=2,459)$ \\
\hline \multicolumn{5}{|l|}{ Demographics } \\
\hline \multirow[t]{4}{*}{ Age (y) } & $<30$ & $604(34.18)$ & $182(26.30)$ & 786 (31.96) \\
\hline & $30-34$ & $461(26.09)$ & $140(20.23)$ & $601(24.44)$ \\
\hline & $35-39$ & 361 (20.43) & $122(17.63)$ & 483 (19.64) \\
\hline & $\geq 40$ & 341 (19.30) & $248(35.84)$ & 589 (23.95) \\
\hline \multirow[t]{2}{*}{ Residential status } & Documented & $678(38.37)$ & $287(41.47)$ & 965 (39.24) \\
\hline & Undocumented & $1,089(61.63)$ & 405 (58.53) & $1,494(60.76)$ \\
\hline \multirow[t]{4}{*}{ Length of stay (y) } & Below 1 & 479 (27.11) & 184 (26.59) & 663 (26.96) \\
\hline & $2-3$ & $448(25.35)$ & $186(26.88)$ & $634(25.78)$ \\
\hline & $4-6$ & 497 (28.13) & 185 (26.73) & 682 (27.73) \\
\hline & Over 7 & $343(19.41)$ & $137(19.80)$ & 480 (19.52) \\
\hline \multirow[t]{10}{*}{ Nationality } & Bangladeshi & $453(25.64)$ & $17(2.46)$ & $470(19.11)$ \\
\hline & Mongolian & $131(7.41)$ & $174(25.14)$ & 305 (12.40) \\
\hline & Filipino & $116(6.56)$ & 166 (23.99) & $282(11.47)$ \\
\hline & Vietnamese & 173 (9.79) & $81(11.71)$ & 254 (10.33) \\
\hline & Sli Lankan & 203 (11.49) & 13 (1.88) & $216(8.78)$ \\
\hline & Chinese & $70(3.96)$ & $108(15.61)$ & $178(7.24)$ \\
\hline & Pakistani & $127(7.19)$ & $0(0)$ & $127(5.16)$ \\
\hline & Indonesian & $95(5.38)$ & $28(4.05)$ & $123(5.00)$ \\
\hline & Thai & $51(2.89)$ & $53(7.66)$ & $104(4.23)$ \\
\hline & Others & 348 (19.69) & $52(7.51)$ & $403(16.27)$ \\
\hline \multicolumn{5}{|c|}{ Incidence of chronic diseases } \\
\hline \multirow{2}{*}{ Hypertension } & No & $1,153(67.07)$ & 504 (74.78) & $1,657(69.24)$ \\
\hline & Yes & $566(32.93)$ & $170(25.22)$ & $736(30.76)$ \\
\hline \multirow[t]{2}{*}{ Diabetes } & No & $1,104(84.60)$ & 497 (91.19) & $1,601(86.54)$ \\
\hline & Yes & $201(15.40)$ & $48(8.81)$ & 249 (13.46) \\
\hline \multirow[t]{2}{*}{ Dyslipidemia } & No & 1,140 (86.69) & $498(87.22)$ & 1,638 (86.85) \\
\hline & Yes & 175 (13.31) & 73 (12.78) & 248 (13.15) \\
\hline \multirow[t]{2}{*}{ Obesity } & No & $1,038(64.23)$ & 445 (69.75) & $1,483(65.79)$ \\
\hline & Yes & 578 (35.77) & 193 (30.25) & $771(34.21)$ \\
\hline \multicolumn{5}{|l|}{ Infectious disease } \\
\hline \multirow[t]{2}{*}{ HBsAg } & No & $1,547(96.75)$ & $590(97.20)$ & 2,147 (96.80) \\
\hline & Yes & $52(3.25)$ & $17(2.80)$ & $71(3.20)$ \\
\hline \multirow[t]{2}{*}{ HIV } & No & 1,549 (99.94) & 592 (99.83) & 2,154 (99.91) \\
\hline & Yes & $1(0.06)$ & $1(0.17)$ & $2(0.09)$ \\
\hline \multirow[t]{2}{*}{ VDRL } & No & 1,585 (99.12) & 605 (99.83) & 2,202 (99.32) \\
\hline & Yes & $14(0.88)$ & $1(0.17)$ & $15(0.68)$ \\
\hline
\end{tabular}

HBsAg: hepatitis B surface antigen, HIV: human immunodeficiency virus, VDRL: venereal disease research laboratory. 


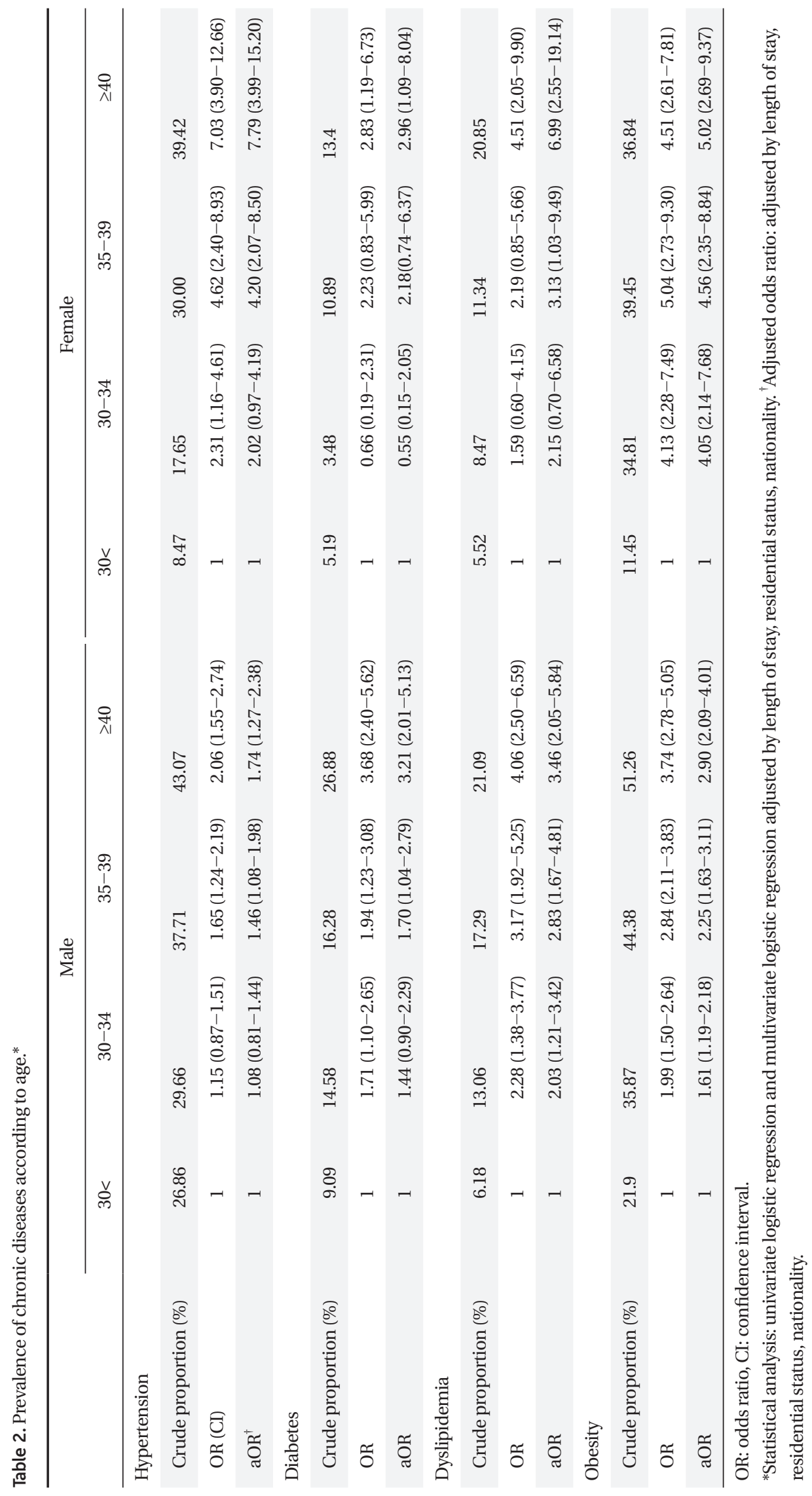


years and $34.6 \%$ for those over 7 years. After adjusting by 'age,' 'residential status,' and 'nationality,' those with length of stay of 4-6 years had higher rates of hypertension than those with less than 1 year (adjusted odds ratio [aOR] 1.39; confidence interval [CI], 1.01 to 1.92 ). In case of diabetes, the prevalence was higher for those with long-stay than those with short stay but no statistical significance was observed after adjustments. In case of dyslipidemia, the prevalence was found to be $8.1 \%$ for those with length of stay was less than 1 year, where it was $14.0 \%$ for those with $2-3$ years, $13.7 \%$ for those with $4-6$ years, and $18.9 \%$ for those with over 7 years. In case of length of stay was over 7 years, it still had higher prevalence than less-than-1-year case after the adjustments (aOR, 1.95; CI, 1.05 to 3.64). The prevalence of obesity was also found to be higher for long-stay group, and still after adjustments, those who stayed $4-6$ years (aOR, 1.65; CI, 1.17 to 2.32 ) and over 7 years (aOR, 1.65; CI, 1.11 to 2.45) were observed to have higher prevalence than those less than 1 year (Table 3).

Meanwhile for female subjects, except for some areas, longstay group also was found to have higher prevalence of chronic diseases like hypertension, diabetes, dyslipidemia, obesity, etc., before adjustments; there observed no statistical significance after adjusting with 'age,' 'nationality,' 'residential status,' etc. (Table 3).

\section{Residential Status Related Prevalence of Chronic Diseases}

In case of male subjects, undocumented migrant group regarding eligibility to stay was found to have higher prevalence of hypertension, diabetes, dyslipidemia, obesity, etc., compared to documented counterpart, but after adjusting by 'age,' 'length of stay,' and 'nationality' no statistical significance was observed. In case of female subjects on diabetes and obesity, undocumented group on eligibility to stay had higher prevalence rates than documented counterpart, but after adjustment, no statistical significance was observed (Table 4).

\section{DISCUSSION}

Increase in number of migrants is not only a Korean phenomenon but also a global trend. According to a 2008 United Nations report, there exit 214 million migrants worldwide, which accounts for $3.1 \%$ of the global population. ${ }^{12)}$ The number of migrants on the increase shows that the world economy cannot continue to survive without migrants' man power. Also, 2030 million of them i.e., the $10 \%-15 \%$ of total migrants are undocumented, ${ }^{13)}$ and this percentage rate has been steady without any big changes. For these reasons, the International Convention on the protection of the rights of all migrant workers and members of their families ${ }^{14)}$ declares that no dignity of man should be violated depending on their eligibility to stay that regardless of their eligibility to stay they have the rights to live a humane life and not discriminated from social welfare. Their various social and economical situations are causing health inequities, for that the International Organization of Migration and the International Labor Organization and the likes are proposing to take special attentions to migrants' health problems, ${ }^{13)}$ and many literatures are stating the needs for providing culturally competent healthcare system to migrants. ${ }^{15)}$

Through various studies of the past, it has been noticed that migrants' prevalence of hypertension, diabetes, dyslipidemia, obesity, etc. are high. ${ }^{16,17)}$ Various accounts have been attempted to explain some mechanisms for their high prevalence. One study reported their urbanized living habits ${ }^{18)}$ and the other reported their low socio-economic status are associated with their hypertension. ${ }^{19)}$ In another studies, they reports that stress from adjusting to their new environments affects their health ${ }^{20)}$ that a group more adjusted to their new cultural surroundings had lower prevalence of hypertension and that this adjustments are associated with their level of material resources and social networks. ${ }^{21)}$ It was also reported that westernized eating habits, lowered physical activities from cultural and economical reasons, stress, racial reasons, ${ }^{22)}$ etc. are causing obesity and type 2 diabetes.

This study analyzed the Migrant Health Association's ${ }^{23)}$ data of their free health screening program in Seoul and Gyeonggido area between year 2004 and 2008. In case of free health screening tour, many undocumented migrants of low access to regular healthcare system tend to participate in these programs, and also in this study the number of undocumented migrants accounted to $60.8 \%$ of total participants, more than the number of documented migrants. Considering $70 \%-80 \%$ of migrants in the country are documented, this sample cannot be said to represent the national migrants. In addition, male accounted for 


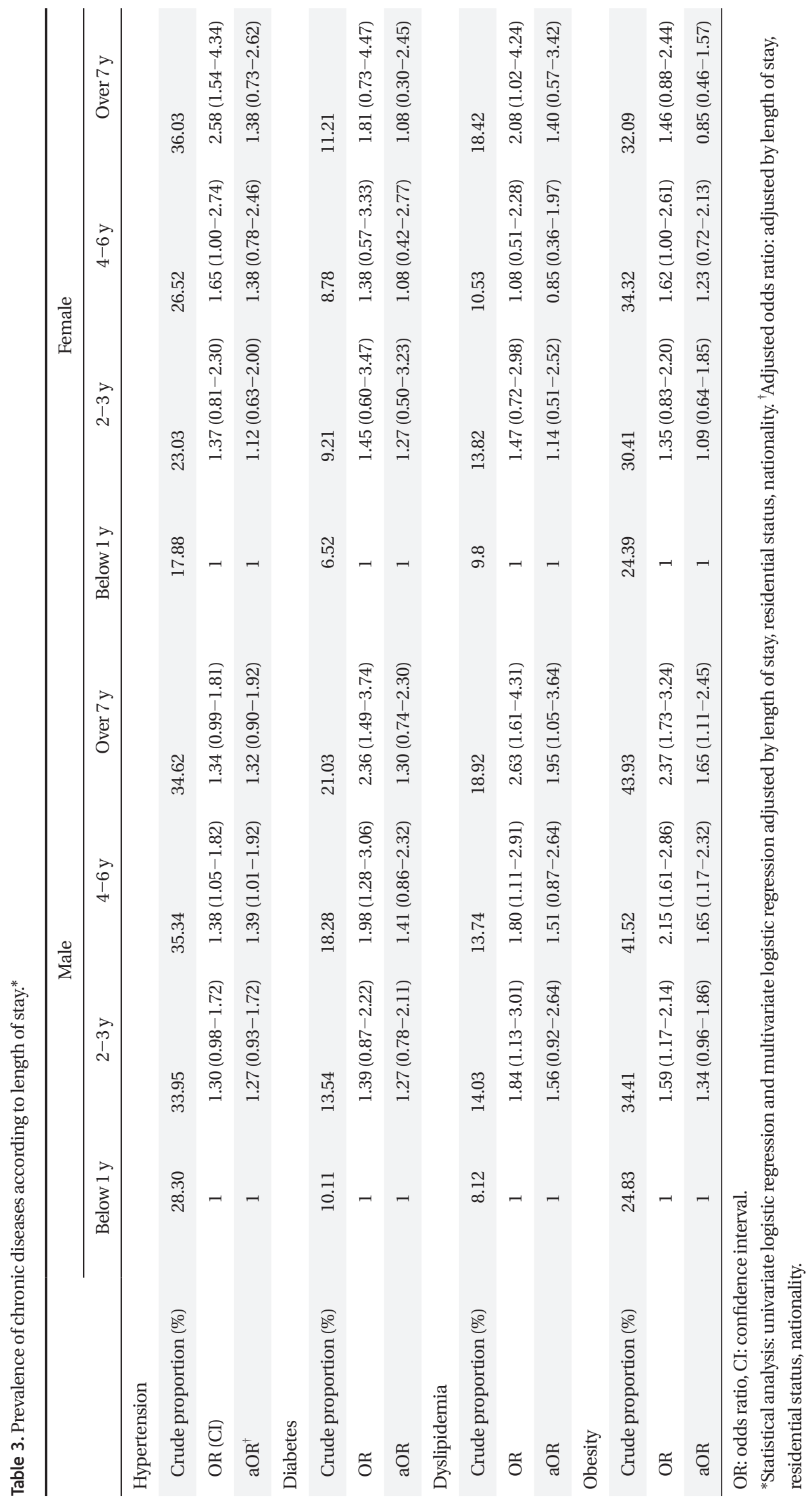


$71.9 \%$ of the total participants and the number of female was only 692 which was too few for a sample that it was hard to guarantee statistical significance in female group analysis.

The migrant group of this study also had high prevalence of hypertension, diabetes, dyslipidemia and obesity that considering their lengths of stay are on the increase and their age are getting older it is required to plan for an adequate management regarding their chronic diseases.

The migrants of this study subjects showed to have significantly higher prevalence of hypertension, diabetes, dyslipidemia, and obesity than people from the same age groups of the 2005 National Health and Nutritional Survey, which is a representative sample for South Korean. In case of male hypertension, the migrant group in their thirties had about twice the rate of Korean counterpart (29.7\% for migrants in their age $30-34 ; 37.7 \%$ for $35-39 ; 14.1 \%$ for Koreans in their thirties, 2005 National Health and Nutritional Survey), and in case of female hypertension, it was found to have surprisingly five times higher prevalence rate than Korean counterpart (17.7\% for migrants in their age $30-34 ; 30.0 \%$ for $35-39 ; 3.1 \%$ for Koreans in their thirties, 2005 National Health and Nutritional Survey). It is hard to state them in generalization on these disparities in the prevalence of hypertension for they were not analyzed by same age and sex groups and existence of bias in samples, but it suggests a call for future representative research. Other studies, also, consistently have suggested that the migrants' prevalence rates of diabetes, dyslipidemia, obesity, etc. are higher than Koreans' that analysis on prevalence rates based on highly credible data is urgently needed.

An Indian study $(2009)^{16)}$ reported that hypertension are common in young migrants from stress of initial adjusting process and their prevalence tend to increase as their length of stay increase. This is a similar case to our case, showing many younger aged migrant groups had hypertension.

Table 4. Prevalence of chronic diseases according to residential status.*

\begin{tabular}{|c|c|c|c|c|}
\hline & \multicolumn{2}{|c|}{ Male } & \multicolumn{2}{|c|}{ Female } \\
\hline & Documented & Undocumented & Documented & Undocumented \\
\hline \multicolumn{5}{|l|}{ Hypertension } \\
\hline Crude proportion (\%) & 31.8 & 33.61 & 25.98 & 24.68 \\
\hline $\mathrm{OR}(\mathrm{CI})$ & 1 & $1.08(0.88-1.34)$ & 1 & $0.93(0.66-1.33)$ \\
\hline $\mathrm{aOR}^{\dagger}$ & 1 & $0.88(0.69-1.14)$ & 1 & $0.68(0.44-1.07)$ \\
\hline \multicolumn{5}{|l|}{ Diabetes } \\
\hline Crude proportion (\%) & 11.18 & 18.11 & 8.00 & 9.38 \\
\hline OR & 1 & $1.76(1.26-2.44)$ & 1 & $1.19(0.65-2.19)$ \\
\hline $\mathrm{aOR}$ & 1 & $1.13(0.77-1.67)$ & 1 & $1.13(0.55-2.34)$ \\
\hline \multicolumn{5}{|l|}{ Dyslipidemia } \\
\hline Crude proportion (\%) & 11.11 & 14.56 & 14.66 & 11.50 \\
\hline OR & 1 & $1.36(0.96-1.92)$ & 1 & $0.75(0.46-1.24)$ \\
\hline $\mathrm{aOR}$ & 1 & $1.12(0.74-1.72)$ & 1 & $0.59(0.31-1.12)$ \\
\hline \multicolumn{5}{|l|}{ Obesity } \\
\hline Crude proportion (\%) & 30.76 & 38.79 & 25.57 & 33.51 \\
\hline OR & 1 & $1.43(1.15-1.77)$ & 1 & $1.46(1.03-2.08)$ \\
\hline $\mathrm{aOR}$ & 1 & $0.97(0.75-1.27)$ & 1 & $1.39(0.92-2.13)$ \\
\hline
\end{tabular}

OR: odds ratio, CI: confidence interval.

*Statistical analysis: Univariate logistic regression and multivariate logistic regression adjusted by length of stay, residential status, nationality.

${ }^{\dagger}$ Adjusted odds ratio: adjusted by length of stay, residential status, nationality. 
This study showed a high tendency in the prevalence rates of chronic diseases like hypertension, diabetes, dyslipidemia, obesity, etc. for both male and female long-stay groups. Especially for male subjects regarding hypertension, dyslipidemia, and obesity, they were found to have statistical differences between certain groups even after adjusting by 'age,' 'nationality,' 'residential status,' etc.

According to Park et al., ${ }^{24)}$ the migrant workers work in average of 10 hours per day, many are on 12-hour shift works and only 23.6\% do regular exercises, according to the Employment Permit System, migrant workers, many of which are of our concern, usually live alone in Korea without their family members. In addition, their living environment is poor and they usually transfer most of their incomes to their home countries and keep small amounts for their own that we could assume they wouldn't spend much money on healthy diet or costly exercises.

Generally, undocumented migrants have more cumulated stresses, ${ }^{25)}$ and these continuous stresses would increase allostatic loads for them to have high prevalence of chronic diseases like hypertension, ${ }^{26)}$ but in this study, no significant differences were observed.

According to studies made at home and abroad, undocumented migrants have higher depression rates, ${ }^{27)}$ and studies abroad also have reported that they visit more frequently to emergency rooms. ${ }^{28)}$ Thus, I'd like to say that we need researches about mental diseases like depression, anxiety, etc. differences in control rates of chronic diseases depending on their reduced access rates to regular healthcare system and in their usage rates of emergency rooms.

Limits of this research were that since it could not be assumed that the blood test numbers are from fasting blood samples that their accuracy could not be verified and that since it cannot be checked whether subjects were under any prescriptions or treatments for their chronic diseases that the prevalence rates could not be calculated more accurately. Since blood test and measuring blood pressure were operated only once that it could not fulfill diagnostic guidelines. Since there were no accompanying surveys that not enough adjustments were done with various affecting factors to chronic diseases. In addition, since this is not a cohort study observing health states on their arrival to Korea then on their transitions in time that it is has limitations of a cross-sectional study. From now on, through systemic research planning, researches on migrants' chronic disease prevalence rates, factors affecting the prevalence and controlling the chronic diseases are urgently needed.

The number of migrants in Korea is on the increase, and now they are an important part of our society. The health of migrants has significant effect on reducing socio-economic costs and on social integration. For managing chronic diseases, recent studies have suggested needs for interruptions through socio-ecological model $^{29)}$ that, henceforth, developing adequate policies through analyzing political, social, cultural, and environmental factors to ensure health equity is one of many challenges Korean society is facing.

\section{CONFLICT OF INTEREST}

No potential conflict of interest relevant to this article was reported.

\section{REFERENCES}

1. Korea Immigration Service Ministry of Justice. KIS statistics 2009. Seoul: Korea Immigration Service Ministry of Justice; 2010.

2. Amnesty International. Disposable labour: rights of migrant workers in South Korea. London: Amnesty International Publications; 2009.

3. Seol DH, Choi HY, Han KS; Chonbuk National University Social Science Research Institute; Joint Committee with Migrants in Korea. Survey for migrant workers human rights in Korea 2002. Seoul: National Human Rights Commission of the Republic of Korea; 2002.

4. Lee SW, Kim KS, Kim TW. The status and characteristics of industrial accidents for migrant workers in Korea compared with native workers. Korean J Occup Environ Med 2008;20: 351-61.

5. Kim OS, Baik SH, Kim KH. The relationships among social support, stress, and loneliness in migrant Yanbian Korean workers. J Korean Acad Adult Nurs 2003; 15:607-16.

6. Seol DH, Hong SK, Goh HU, Kim IT. Survey on the health conditions of migrant workers in Korea. Seoul: Korea Foundation for International Healthcare; 2005. 
7. Mackenbach JP, Bakker MJ; European Network on Interventions and Policies to Reduce Inequalities in Health. Tackling socioeconomic inequalities in health: analysis of European experiences. Lancet 2003;362:1409-14.

8. Cooper R, Rotimi C. Hypertension in populations of West African origin: is there a genetic predisposition? J Hypertens 1994; 12:215-27.

9. Hong SK, Ou SW, Lim KE, Choi KM, Cho BL, Huh BY. A study of medical utilization and health status for migrant workers in Korea. J Korean Acad Fam Med 2000;21:1053-64.

10. Lee HY, Stephania S, Cho YI, Choi EY, Park JA, Park YM. Health status of migrant workers in Korea. Korean J Occup Health Nurs 2009; 18:5-13.

11. Kaushal N. Adversities of acculturation? Prevalence of obesity among immigrants. Health Econ 2009; 18:291-303.

12. Population Division, Department of Economic and Social Affairs, United Nations. Trends in international migrant stock: the 2008 revision. New York: Population Division, DESA, United Nations; 2009.

13. International Labour Office. Towards a fair deal for migrant workers in the global economy. Geneva: International Labour Office; 2004.

14. Center for Migration Studies (US). International Convention on the protection of the rights of all migrant workers and members of their families. New York: Center for Migration Studies of New York; 1991.

15. Anderson LM, Scrimshaw SC, Fullilove MT, Fielding JE, Normand J; Task Force on Community Preventive Services. Culturally competent healthcare systems: a systematic review. Am J Prev Med 2003;24(3 Suppl):68-79.

16. Kusuma Y, Gupta S, Pandav C. Migration and hypertension: a cross-sectional study among neo-migrants and settledmigrants in Delhi, India. Asia Pac J Public Health 2009;21: 497-507.

17. Misra A, Ganda OP. Migration and its impact on adiposity and type 2 diabetes. Nutrition 2007;23:696-708.

18. Gupta R. Trends in hypertension epidemiology in India. J
Hum Hypertens 2004;18:73-8.

19. Reddy KK, Rao AP, Reddy TP. Socioeconomic status and the prevalence of coronary heart disease risk factors. Asia Pac J Clin Nutr 2002;11:98-103.

20. Gershater E, McGarvey ST. Fourteen year changes in adiposity and blood pressure in American Samoan adults. Am J Hum Biol 1995;7:597-606.

21. Thomas RB. The evolution of human adaptability paradigms: toward a biology of poverty. In: Goodman AH, Leatherman TL, editors. Building a new biocultural synthesis: politicaleconomic perspectives on human biology. Ann Arbor: University of Michigan Press; 1998. p. 43-74.

22. Berkman LF. The role of social relations in health promotion. Psychosom Med 1995;57:245-54.

23. Migrant Health Association in Korea. mumk.org [Internet]. Seoul: Migrant Health Association in Korea; c2011. [cited 2010 May 21]. Available from: http://mumk.org.

24. Park SM, Jung HS, Kim YK, Lee YJ, Kim ES. Improvement of workplace envirnonment and health for migrant workers. Seoul: Federation of Korean Trade Unions; 2007.

25. Arbona C, Olvera N, Rodriguez N, Hagan J, Linares A, Wiesner M. Acculturative stress among documented and undocumented Latino immigrants in the United States. Hisp J Behav Sci 2010;32:362-84.

26. Seeman TE, Singer BH, Rowe JW, Horwitz RI, McEwen BS. Price of adaptation--allostatic load and its health consequences. MacArthur studies of successful aging. Arch Intern Med 1997;157:2259-68.

27. Sullivan MM, Rehm R. Mental health of undocumented Mexican immigrants: a review of the literature. ANS Adv Nurs Sci 2005;28:240-51.

28. Okie S. Immigrants and health care--at the intersection of two broken systems. N Engl J Med 2007;357:525-9.

29. Cassel KD. Using the Social-Ecological Model as a research and intervention framework to understand and mitigate obesogenic factors in Samoan populations. Ethn Health 2010;15:397-416. 